\title{
Research on Gas Drainage Laws of SRV-fractured Horizontal Wells in Different Types of Tight Gas Reservoirs
}

\author{
Xucheng $\mathrm{Li}^{1}{ }^{1}$, Jian Cao ${ }^{1}$, Yajie Gao ${ }^{1}$, Huiyan Zhao ${ }^{1}$, Zhai Shuo ${ }^{2, *}$ \\ ${ }^{1}$ Northwest Sichuan Division, Petro China Southwest Oil \& Gasfield Company, Jiangyou, Sichuan, China \\ ${ }^{2}$ College of energy, Chengdu University of science and technology, Chengdu, Sichuan, China
}

\begin{abstract}
Horizontal well and large-scale hydraulic fracturing are the main technical means for tight gas development at present. However, tight gas reservoirs are characterized by strong heterogeneity, and different types of gas Wells have different production characteristics and pressure propagation laws. In view of the above problems, based on the physical characteristics and reservoir reconstruction evaluation of tight gas reservoir in GAS Reservoir A in Sichuan Basin, three types of reservoir hydraulic fracture models and numerical simulation models were generated by using numerical simulation method, and the production dynamic prediction and pressure wave propagation law were studied. The simulation results show that: (1) In the beginning of production, the deflated area is mainly hydraulic fracture reconstruction area, and the drainage radius of all kinds of gas Wells expands at similar speed; (2) When the drainage range is expanded in the untransformed area, the dimensionless drainage radius expansion speed of gas well is positively correlated with the reservoir physical property. The dimensionless drainage radius and drainage area of class I and II horizontal Wells are relatively faster, while that of Class III Wells is slightly slower.
\end{abstract}

Keywords: tight gas, horizontal well, dynamic prediction, drainage laws.

\section{Introduction}

Tight gas is one of the three major unconventional natural gas resources in the world, with abundant reserves. Efficient development of tight gas is of great significance for realizing green energy transformation. However, the density has the characteristics of low porosity, low permeability and low pressure. At present, the technology of long horizontal Wells and large-scale hydraulic fracturing is used for development. However, due to the poor physical properties of the reservoir, the economic benefits of tight gas development are reduced. Therefore, it is helpful to improve the development effect and economic benefits to carry out seepage law and production dynamic prediction and formulate a relative production management system.

In view of the strong heterogeneity of tight sandstone gas reservoir A in Sichuan Basin, this paper divides the reservoir into three types based on permeability, porosity and other parameters. Based on the established porosity and permeability model and the pressure improvement effect, the numerical simulation models of three types of reservoirs were established, and the production dynamic prediction was carried out, and the relationship between production and pressure drop spread and time of different types of reservoirs was analyzed. The research results of this paper can provide some help for differentiated management and reasonable well spacing evaluation of horizontal Wells in different types of reservoirs.

\section{Construction of numerical simulation models for horizontal Wells in different types of reservoirs}

Table 1. Basic parameters of different types of reservoir numerical simulation models

\begin{tabular}{|c|c|c|c|}
\hline Parameter & Class I & Class II & Class III \\
\hline $\begin{array}{l}\text { The depth of the gas } \\
\text { reservoir }(\mathrm{m})\end{array}$ & 2000 & 2000 & 2000 \\
\hline $\begin{array}{c}\text { Gas reservoir pressure } \\
\qquad(\mathrm{MPa})\end{array}$ & 20 & 20 & 20 \\
\hline $\begin{array}{l}\text { The thickness of the } \\
\text { reservoir }(\mathrm{m})\end{array}$ & 15 & 20 & 25 \\
\hline Reservoir porosity (\%) & 12 & 10 & 8 \\
\hline $\begin{array}{l}\text { Reservoir permeability } \\
(\mathrm{mD})\end{array}$ & 0.1 & 0.05 & 0.01 \\
\hline Gas saturation (\%) & 70 & 60 & 50 \\
\hline The grid size & $10 \times 10 \times 1$ & $10 \times 10 \times 1$ & $10 \times 10 \times 1$ \\
\hline The model size & $\begin{array}{l}3000 \times 1 \\
500 \times 15\end{array}$ & $\begin{array}{l}3000 \times 1 \\
500 \times 20\end{array}$ & $\begin{array}{c}3000 \times 15 \\
00 \times 25\end{array}$ \\
\hline $\begin{array}{l}\text { Perforation length of } \\
\text { horizontal well }(\mathrm{m})\end{array}$ & 800 & 800 & 800 \\
\hline
\end{tabular}

The main development layer of A gas reservoir in Sichuan Basin is Jurassic Shaximiao Formation. Based on the

\footnotetext{
* Corresponding author: 2020050127@stu.cdut.edu.cn
} 
development experience of CNPC and SINOPEC in Jurassic Shaximiao Formation, the reservoirs can be divided into three types. The physical parameters related to different types of reservoirs are shown in Table 1.

The development of tight gas in block A of Sichuan Basin mainly adopts the technology of horizontal well and largescale hydraulic fracturing, in which the fracturing technology mainly selects multi-cluster perforation in stages and continuous sand addition of slickwater to form tight fractures in the reservoir, so as to improve the reservoir reconstruction effect. Based on the mathematical models of different types of reservoir permeability and the related parameters in Table 1, the combination of three kinds of typical Wells reservoir fracturing operation evaluation results of the MLF-P3D model, produce all kinds of corresponding hydraulic fracture reservoir model, and on the basis of hydraulic model with unstructured grid generation numerical simulation model, three kinds of reservoir numerical simulation model is shown in Figure 1.

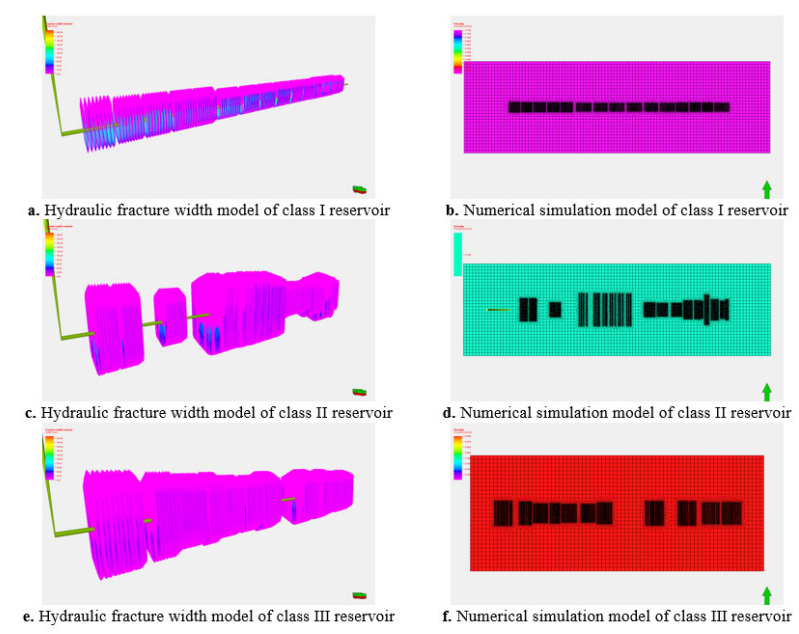

Figure 1. Hydraulic fracture width models and numerical simulation grid profiles of typical horizontal Wells in various reservoirs

\section{Study on dynamic simulation and deflation law of horizontal Wells in different types of reservoirs}

The numerical simulation model is used to simulate the horizontal production of different types of reservoirs, and the propagation characteristics of horizontal well pressure in different types of reservoirs are mastered.

\subsection{Production forecast of different types of horizontal Wells}

(1) Production prediction of horizontal Wells in Class I reservoirs

Based on the established production grid model, the production of typical Wells in class I reservoir was predicted. The wells were set to produce at a stable rate of $10 \times 10^{4} \mathrm{~m}^{3} / \mathrm{d}$ and the 20-year development index was predicted. The production curve is shown in Figure 2. As can be seen from the figure, when the horizontal well of class I reservoir is produced at the rate of $10 \times 10^{4} \mathrm{~m}^{3} / \mathrm{d}$, the stable production time is 3.8 years, and the estimated cumulative gas production at the end of the period is $2.69 \times 10^{8} \mathrm{~m}^{3}$.

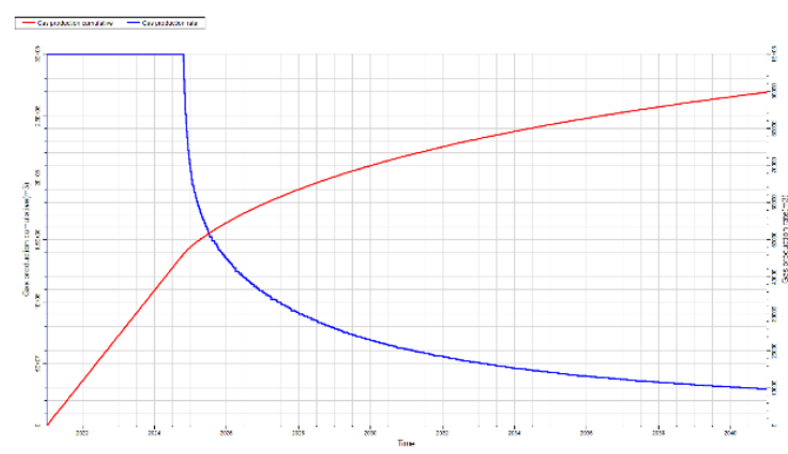

Figure 2. Prediction graph of typical well production curve of class I

Meanwhile, reservoir pressure distribution maps of different production times are obtained, as shown in Figure 3.
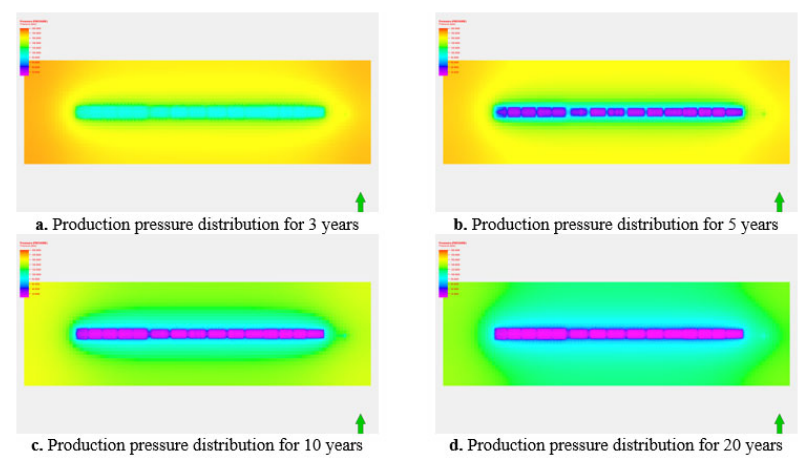

Figure 3. Class I typical wells reservoir pressure distribution of different production time

The dynamic simulation results show that the pressure drop of class I reservoir horizontal wells first reaches the outer boundary of the pressure fracture direction 90 days after production, then reaches the outer boundary of the well axis direction 18-0 days later, and spreads to the whole area 270 days after the pressure drop. At the same time, the equivalent dimensionless drainage radius and dimensionless drainage area of horizontal wells in class I reservoirs after transformation are shown in Figure 4. As can be seen from the figure, the equivalent dimensionless drainage radius rose rapidly at the initial stage, reaching 0.5 at 30 days of production and exceeding 0.7 at 90 days of production. The dimensionless drainage area of class I horizontal wells after transformation no longer increases linearly with time, but becomes slightly faster in the early stage and slower in the later stage. 


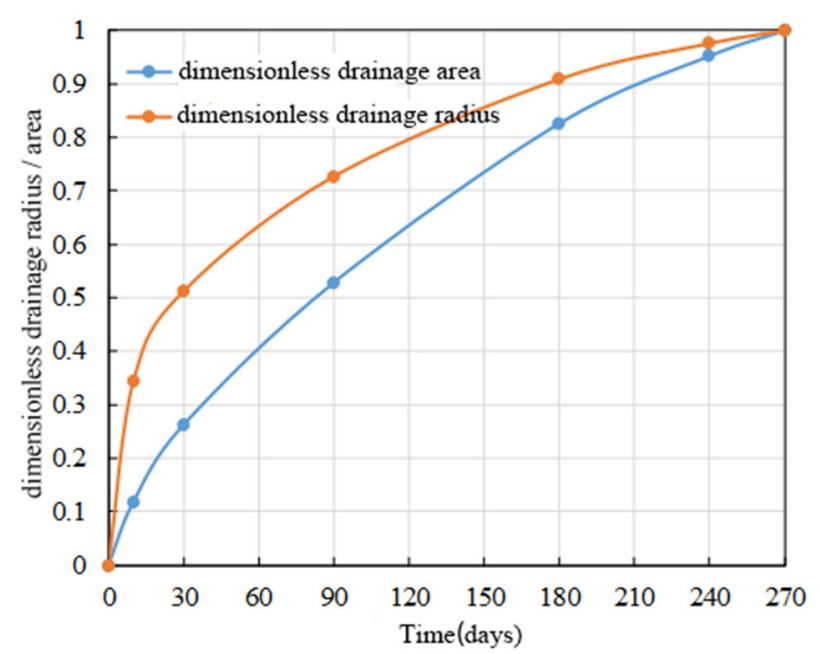

Figure 4. Class I of horizontal well after transforming the equivalent radius of dimensionless drainage and dimensionless drainage area change rule

(2) Class II horizontal well production forecasting reservoir

Based on the established production grid model, the production of horizontal Wells in class II reservoir is predicted. The well was set to produce at a stable rate of $10 \times 10^{4} \mathrm{~m}^{3} / \mathrm{d}$, and the 20 -year development index was predicted. The production curve is shown in Figure 5. As can be seen from Figure 5, when the horizontal well of class II reservoir is produced at the rate of $10 \times 10^{4} \mathrm{~m}^{3} / \mathrm{d}$, the stable production time is 11 months, and the estimated cumulative gas production at the end of the period is $1.57 \times 10^{8} \mathrm{~m}^{3}$.

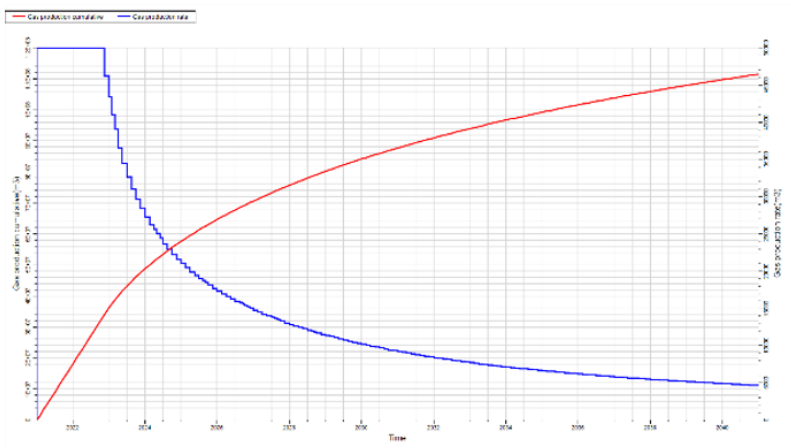

Figure 5. Class II typical wells production figure curve prediction

At the same time the reservoir pressure drawing of the different production time, as shown in Figure 6. The pressure drop of class II horizontal wells first reaches the outer boundary of the pressure fracture direction about 180 days after transformation, and then reaches the outer boundary of the well axis direction about 270 days later. The expansion rate of the drainage radius is slightly slower than that of class I wells.

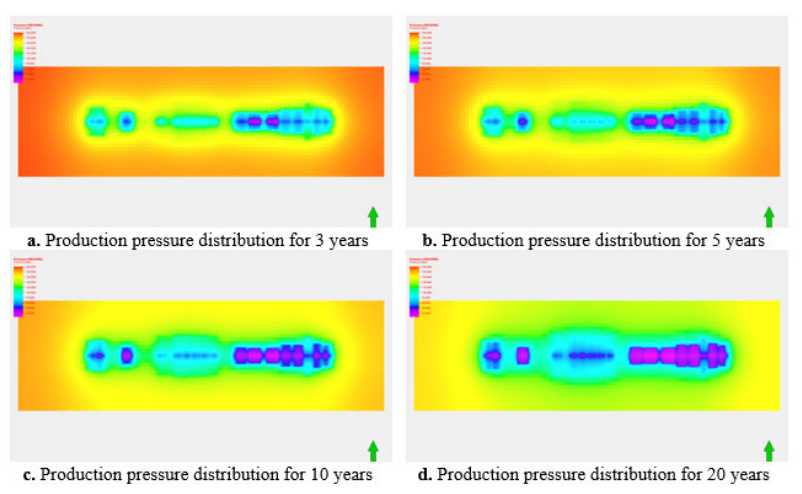

Figure 6. Class II typical wells reservoir pressure distribution of different production time

Changes of equivalent dimensionless drainage radius and dimensionless drainage area of class II horizontal wells after transformation. As can be seen from the figure, the equivalent dimensionless drainage radius rose rapidly in the initial stage, and the dimensionless drainage radius exceeded 0.5 at 50 days and 0.7 at 150 days. The dimensionless drainage area of class II horizontal wells after transformation increases rapidly with the early time, and basically increases linearly after 100 days, and the pressure drop spreads to the whole area for about 500 days.

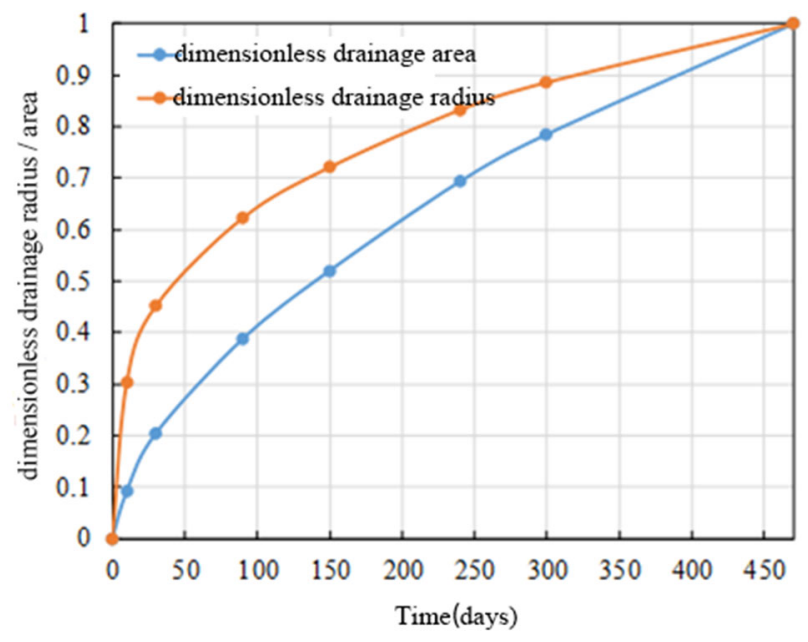

Figure 7. Changes of equivalent dimensionless drainage radius and dimensionless drainage area of class II horizontal wells after transformation

(3) Class III reservoir horizontal well production forecasting

Class III based on manufacturing grid model, reservoir horizontal well production forecast, set well with $5 \times 10^{4} \mathrm{~m}^{3} / \mathrm{d}$ stable yield rate of production, Predict 20 years development, the production curve is shown in Figure 8 . Can be seen from the diagram, the class III typical Wells at a rate of about $5 \times 10^{4} \mathrm{~m}^{3} / \mathrm{d}$ production, stable yield of 2.9 years, Forecast the final tired gas $1.12 \times 10^{8} \mathrm{~m}^{3}$. 


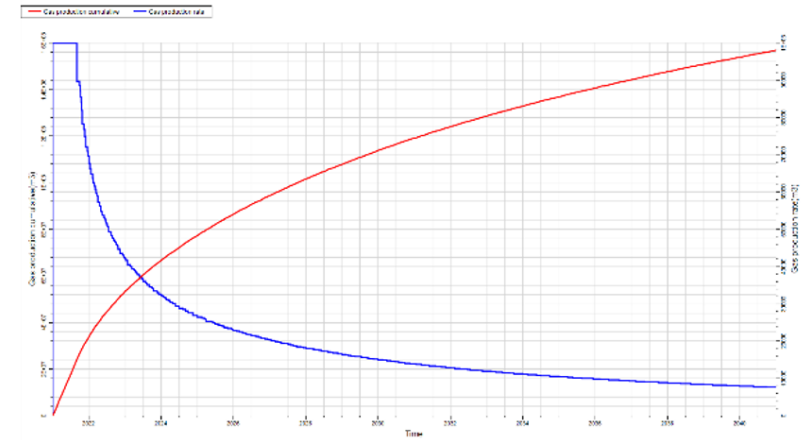

Figure 8. Class III typical wells production figure curve prediction

At the same time the reservoir pressure drawing of the different production time, as shown in Figure 9. Class III regularity of the frustrated radius horizontal well after transforming. Can be seen from the diagram, the class III pressure of horizontal well after about 360 days to reach outer boundary, compressive fracture direction to the shaft axis in 720 days, Frustrated radius expanding speed significantly slower than class I and II wells.

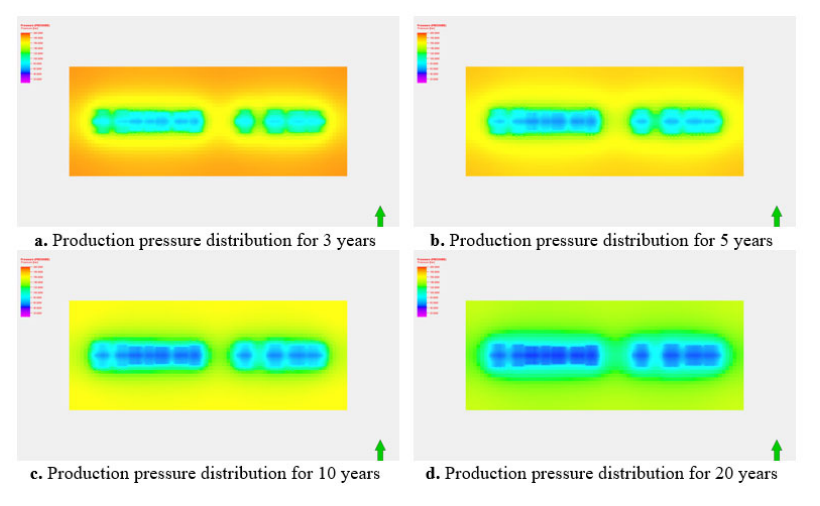

Figure 9. Class III typical wells reservoir pressure distribution of different production time

Figure for class II 3-2-16 horizontal well after transforming the equivalent radius of dimensionless drainage and dimensionless drainage area change rule. As can be seen from the diagram, the equivalent radius of dimensionless drainage early rise faster, to produce 50 days dimensionless drainage radius more than $0.5,150$ days radius of dimensionless frustrated over 0.7; Class II horizontal well after transforming dimensionless drainage area over time early increase quickly, basic linear increase after 100 days, pressure drop across the whole area of about 500 days.

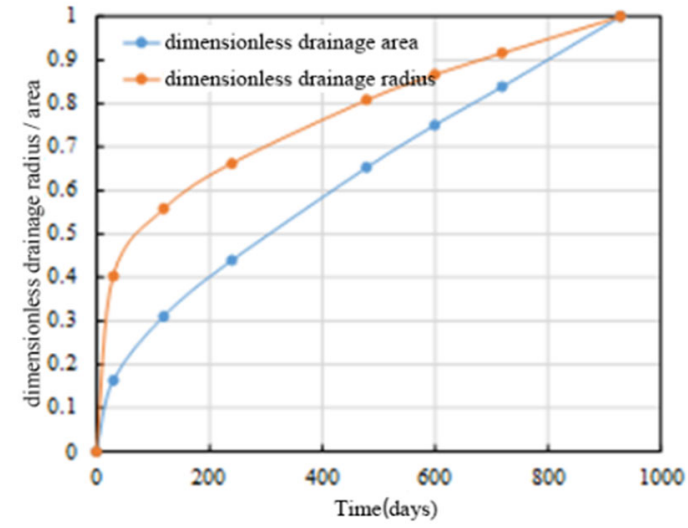

Figure 10. Class III horizontal well after transforming the equivalent radius of dimensionless drainage and dimensionless drainage area change rule

\subsection{All kinds of horizontal well patterns discouraged}

Figure 11 for different types of horizontal well after transforming the equivalent radius of dimensionless drainage and dimensionless drainage area of contrast. As you can see, all kinds of horizontal well in the early development of dimensionless drainage radius extended nearly, after a period of time, class I and class II horizontal radius of dimensionless drainage and drainage area is relatively fast, and class III well a bit slower than I, II class well.

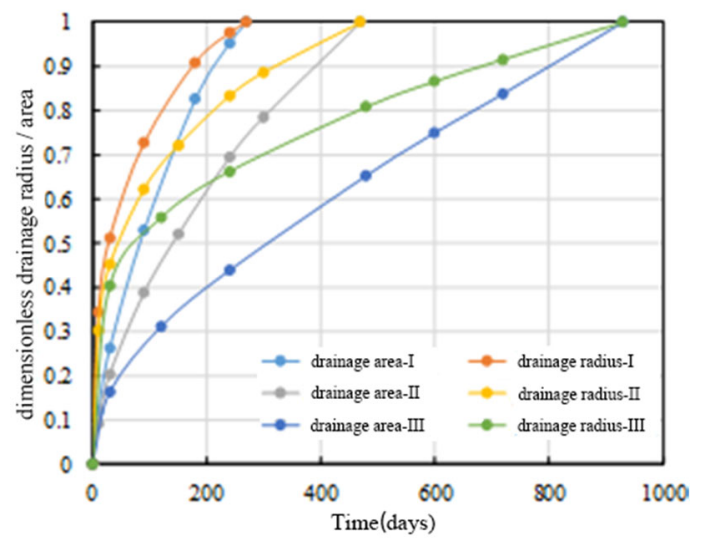

Figure 11. Different types of horizontal well after transforming the equivalent radius of dimensionless drainage and dimensionless drainage area of contrast

Table 2. Different types of gas reservoir pressure wave propagation time relates to the extent

\begin{tabular}{cccc}
\hline $\begin{array}{c}\text { Travel time } \\
\text { The pressure }\end{array}$ & $\begin{array}{c}\text { Class } \\
\text { I } \\
\text { (dave propagation distance }\end{array}$ & $\begin{array}{c}\text { Class } \\
\text { II } \\
\text { (days) }\end{array}$ & $\begin{array}{c}\text { Class } \\
\text { III } \\
\text { (days) }\end{array}$ \\
\hline $\begin{array}{c}\text { SRV area } \\
\text { Outer boundary fracture } \\
\text { direction }\end{array}$ & 10 & 30 & 30 \\
$\begin{array}{c}\text { The horizontal axis outer } \\
\text { boundary }\end{array}$ & 90 & 180 & 240 \\
$\begin{array}{c}\text { Outer boundary reservoir } \\
\text { The all control area }\end{array}$ & 270 & 270 & 360 \\
\hline
\end{tabular}




\section{Conclusion}

(1) In order to study the relationship between the variation law of reservoir drainage range and reservoir physical properties of fractured horizontal wells in tight gas reservoirs, a single well numerical simulation model was established for three types of reservoirs, and production performance prediction was carried out.

(2) In the early stage of development, the velocity of nondimensional drainage radius expansion of all types of horizontal wells is close. After a period of time, the nondimensional drainage radius and drainage area of class I and II horizontal wells are relatively fast, while class III wells are slightly slower than class I and II wells.

\section{References}

1. Shengli Li, Y.Zee Ma, Ernest Gomez. Importance of Modeling Heterogeneities and Correlation in Reservoir Properties in Unconventional Formations: Examples of Tight Gas Reservoirs[J].Journal of Earth Science, 2021, 32(04): 809-817.

2. Jie Wang,Fu-Jian Zhou.Cause analysis and solutions of water blocking damage in cracked/non-cracked tight sandstone gas reservoirs [J]. Petroleum Science, 2021, 18(01): 219-233.

3. CUI Mingming,FAN Aiping,WANG Zongxiu,GAO Wanli,LI Jinbu,LI Yijun.A Volumetric Model for Evaluating Tight Sandstone Gas Reserves in the Permian Sulige Gas Field,Ordos Basin,Central China [J]. Acta Geologica Sinica(English Edition), 2019, 93(02): 386-399.

4. Ya-Hao Huang,You-Jun Tang,Mei-Jun Li,Hai-Tao Hong,Chang-Jiang Wu,Ji-Zhen Zhang,Xiao-Lin Lu,Xiao-Yong Yang.Quantitative evaluation of geological fluid evolution and accumulated mechanism: in case of tight sandstone gas field in central Sichuan Basin [J]. Petroleum Science, 2021, 18(02): 416-429.

5. Yu-Liang Su,Jin-Gang Fu,Lei Li,Wen-Dong Wang,Atif Zafar,Mian Zhang,Wei-Ping Ouyang.A new model for predicting irreducible water saturation in tight gas reservoirs [J]. Petroleum Science, 2020, 17(04): 1087-1100.

6. SUN Hedong, OUYANG Weiping, ZHANG Mian, TANG Haifa, CHEN Changxiao, MA Xu, FU Zhongxin. Advanced production decline analysis of tight gas wells with variable fracture conductivity [J]. Petroleum Exploration and Development, 2018, 45(03): 472-480.

7. LI Mi, GUO Yinghai, LI Zhuangfu, WANG Huaichang, ZHANG Jingxia. Pore-Throat Combination Types and Gas-Water Relative Permeability Responses of Tight Gas Sandstone Reservoirs in the Zizhou Area of East Ordos Basin, China [J]. Acta Geologica Sinica (English Edition), 2019, 93(03): 622-636.

8. Atif Zafar, Yu-Liang Su, Lei Li, Jin-Gang Fu, Asif Mehmood, Wei-Ping Ouyang, Mian Zhang. Tight gas production model considering TPG as a function of pore pressure, permeability and water saturation [J]. Petroleum Science, 2020, 17(05): 1356-1369.

9. Liang Xue, Shao-Hua Gu, Xie-Er Jiang, Yue-Tian Liu, Chen Yang. Ensemble-based optimization of hydraulically fractured horizontal well placement in shale gas reservoir through Hough transform parameterization [J]. Petroleum Science, 2021, 18(03): 839-851.

10. Botao Lin, Han Meng, Jingjun Pan, Sen Chen. Porothermoelastic response of an oil sand formation subjected to injection and micro-fracturing in horizontal wells [J]. Petroleum Science, 2020, 17(03): 687-700.

11. Jiaxuan LIU, Xinchun SHANG, Weiyao ZHU. Investigation on nonlinear multi-scale effects of unsteady flow in hydraulic fractured horizontal shale gas wells [J]. Applied Mathematics and Mechanics (English Edition), 2018, 39(02): 181-192.

12. TANG Mingming, LU Shuangfang, LIANG Hongru, YAN Bihui, SHEN Shan.Study on the Fracturing Parameters and Productivity of Horizontal Wells [J] .Acta Geologica Sinica (English Edition), 2015, 89(S1): 321-323. 